\title{
Phone Controlled Security Lock Systems
}

\author{
Mohan $\mathbf{M}^{1}$, Vishal Kannan ${ }^{2}$, M Keshav ${ }^{3}$ \\ Student, Mechanical Engineering, RV College of Engineering, Bengaluru, India ${ }^{1,2}$ \\ Assistant Professor, Mechanical Engineering, RV College of Engineering, Bengaluru, India ${ }^{3}$
}

\begin{abstract}
Convenience of operation along with maximal functionality in the daily realms of life is one of the greatest concerns of humanity and is an imperative need for any consumer. Innovation in the field of home security systems has provided a unique synergy of security and technology, but they lack accessibility. This paper tries to solve this problem of accessibility by introducing the concept of "minimal human intervention" while not compromising on security. In this paper, we propose a system to access the door lock using an android application and wireless Bluetooth system and elaborate on all possible scenarios that occur in the event of accessing the door lock system.
\end{abstract}

Keywords: Micro-controller, Bluetooth module, GSM module, IR receiver and blaster.

\section{INTRODUCTION}

The current day door lock requires the need for a physical key or the presence of a human. Every human has the need for convenience and most of the electronic door locks depends on hardware which exist on the wrong side of the door. Due to this, unlocking the door involves multiple inconvenient steps to justify security. This also opens the possibility of tampering of the door locks if one were to do so. In this paper, we have proposed a door lock system that prevents tampering of the lockand enhances the aesthetic nature of the door by having a minimalistic look.

Figure $1 \mathrm{a}$ and $1 \mathrm{~b}$ shows the schematic representation of the door lock being used. Figure 1c shows the threedimensional diametric view. It consists of an IR receiver, comparator, Microcontroller, GSM module, Bluetooth module, servo motors, rack and pinion arrangement of lock.

An infrared reviver or IR receiver is a hardware that sends information from an infrared remote control to another device by relieving and decoding signals. A comparator compares the input voltage with the reference voltage and hence sends the information to microcontroller to perform necessary action. A microcontroller is a control device which incorporates a microprocessor and controls all activities to be performed. It is the brain of our door lock system. A GSM (Global system for mobile communications) module is a chip or a circuit that will be used to establish communication between a mobile device and the GSM system in the door lock. Bluetooth module is a wireless technology standard for exchanging data over short distance from fixed to mobile devices. Servo motors is a rotary actuator that allows for precise control of angular position, velocity and acceleration. It consists of a suitable motor coupled to a sensor for position feedback. Rack and pinion arrangement is coupled with servo motor which is used to lock and unlock the door. Here the rotary motion of the servo motor or the pinion is converted to linear motion of the lock. The rack and pinion is made of case hardened steel in order to keep it long lasting and prevent wear and tear.

The mandatory specification of the mobile includes an IR baster and a SIM card. Most modern android phones will have IR blasters and it will soon become an imperative need for the consumer. It is most likely that an IR blaster will become as essential and common as a camera in the smart phone. Initially IR blasters in phones saw the potential of replacing remotes. In this paper have unleased the potential of the IR blaster in the field of home security system. The phone has an android application to access and control the door lock. The door can be accessed either from close proximity(Bluetooth) or even from far away places through SMS (GSM) which this allows flexibility, versatility and uniqueness to our proposal.

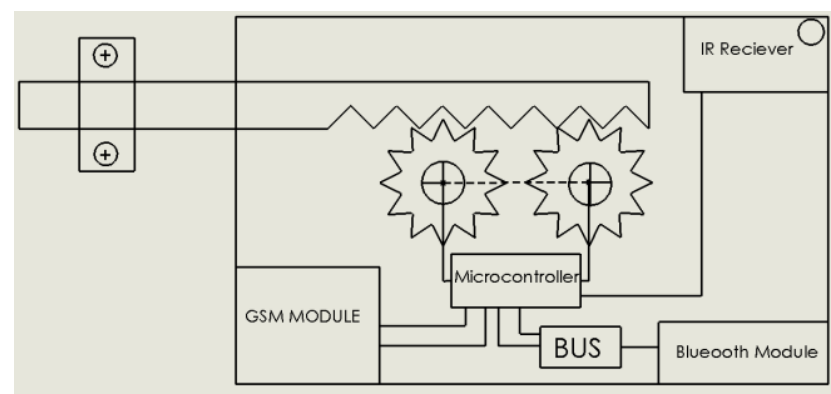

Figure 1a: Lock view from inside 


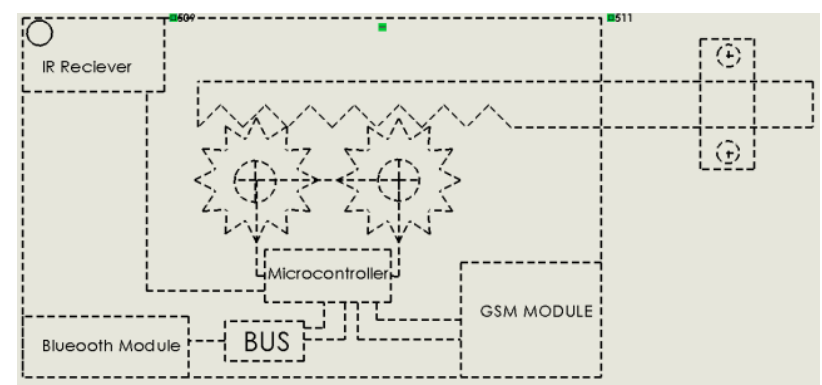

Figure 1b: Lock view from outside

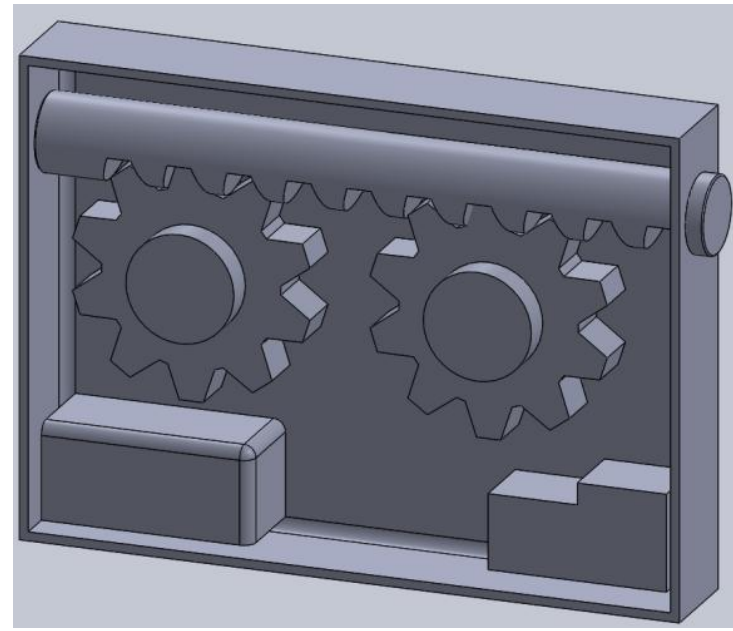

Figure 1c: Diametric View of Door Lock

\section{METHODOLOGY}

The process is initiated by opening the Android application installed in a compatible smartphone. The door can be accessed in two ways namely, through Bluetooth or through SMS. The microcontroller will be programmed so as to perform the necessary operations during execution process. The complete methodology has been explained in the flow chart in Figure 2.

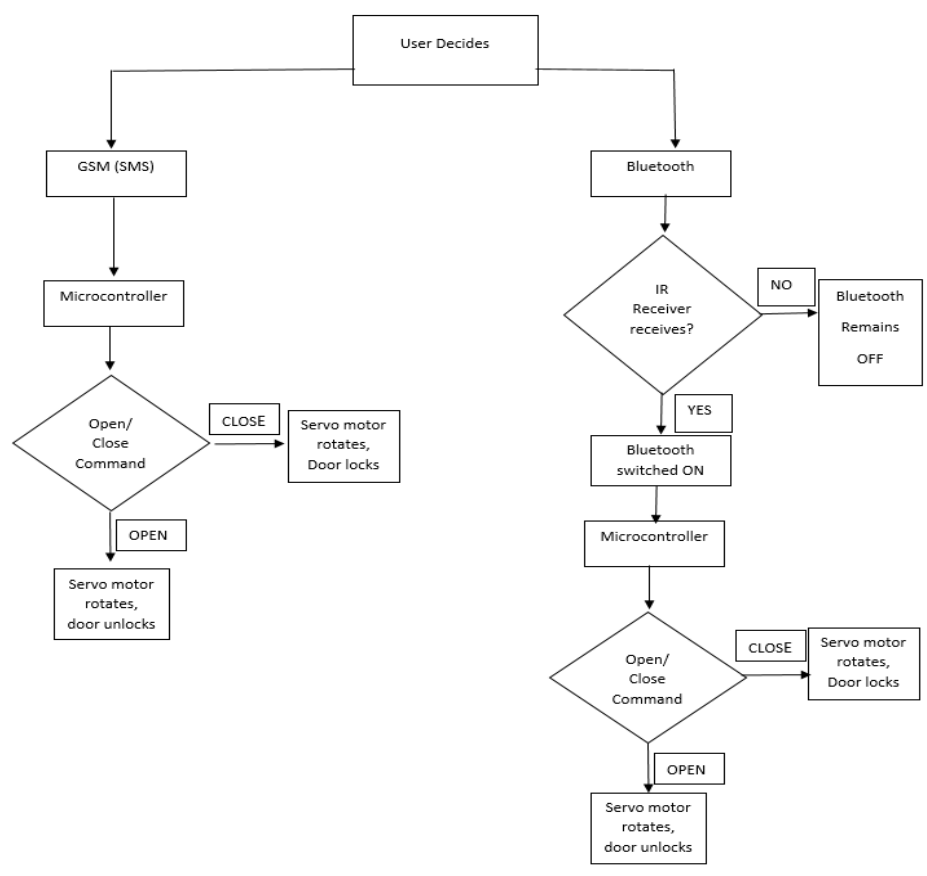

Figure 2: Process flow chart 


\section{A. Bluetooth}

The process is initiated by switching on the IR blaster in the android application, the IR rays are received by the IR receiver through a small hole in the door lock which shown in the figure 1a and $1 \mathrm{~b}$. The IR receiver sends the signal in the form of voltage signal and this voltage is being compared using a comparator with the reference voltage. Thus the comparator inputs a signal to the microcontroller to switch on the Bluetooth module if the input voltage is greater that the reference voltage. The mobile is paired with the Bluetooth module in the door lock by entering a password to enhance security even more. Once the Bluetooth is paired, the application is designed in such a way that it has an "OPEN" and "CLOSE" buttons to unlock and unlock the door respectively.

- When the OPEN button is pressed, the respective frequency signal is sent to the Bluetooth module via Bluetooth wireless technology. Here the Bluetooth module decodes the signal and inputs the meaningful information into the microcontroller. Thus the microcontroller actuates the servo motor to rotate which is coupled with rack and pinion arrangement which shifts the rack into the door lock which allows to access the door. Hence the door unlocks.

- When the CLOSE button is pressed, the respective frequency signal is sent to the Bluetooth module via Bluetooth wireless technology. Here the Bluetooth module decodes the signal and inputs the meaningful information into the microcontroller. Thus the microcontroller actuates the servo motor to rotate in the direction opposite to that of the OPEN button configuration.This is coupled with rack and pinion arrangement which shifts the rack off the door lock which allows the closing of the door. Hence the door locks.

- $\quad$ The schematics of this process have been shown in Figure 3a, 3b and 3c.

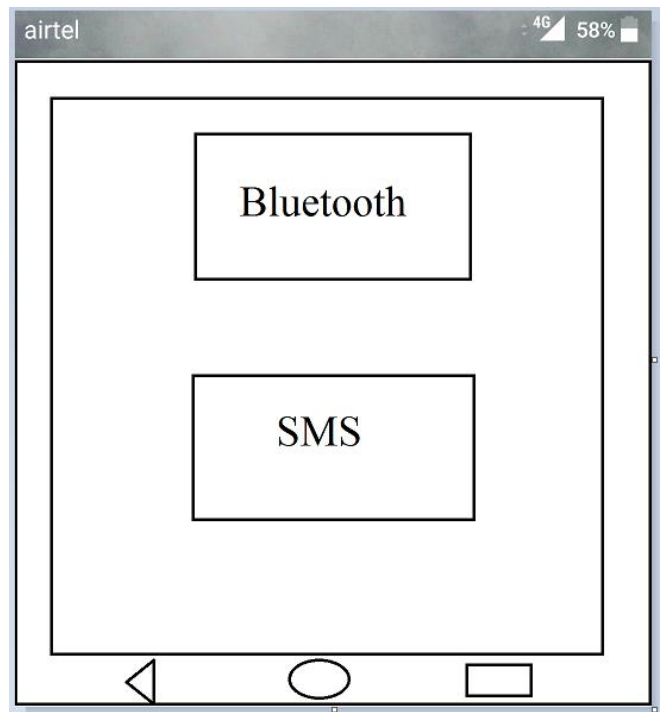

Figure 3a: First step in the application

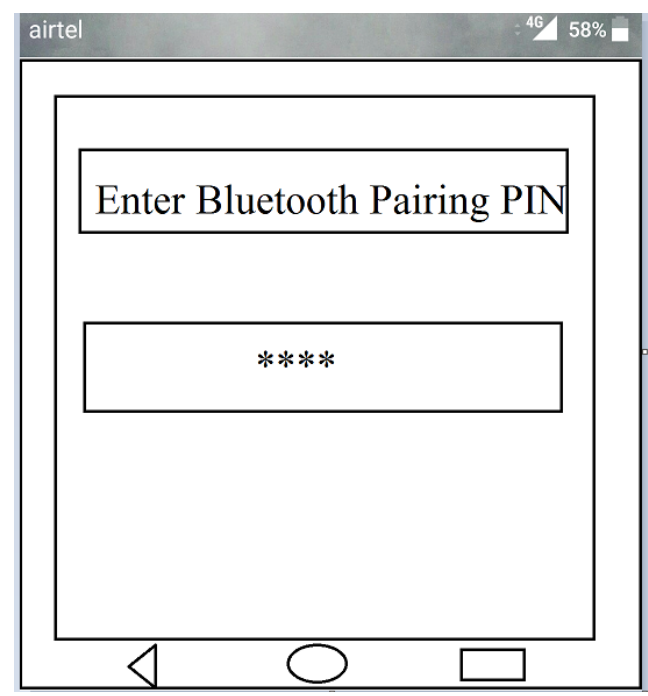

Figure 3b: Pairing Bluetooth 


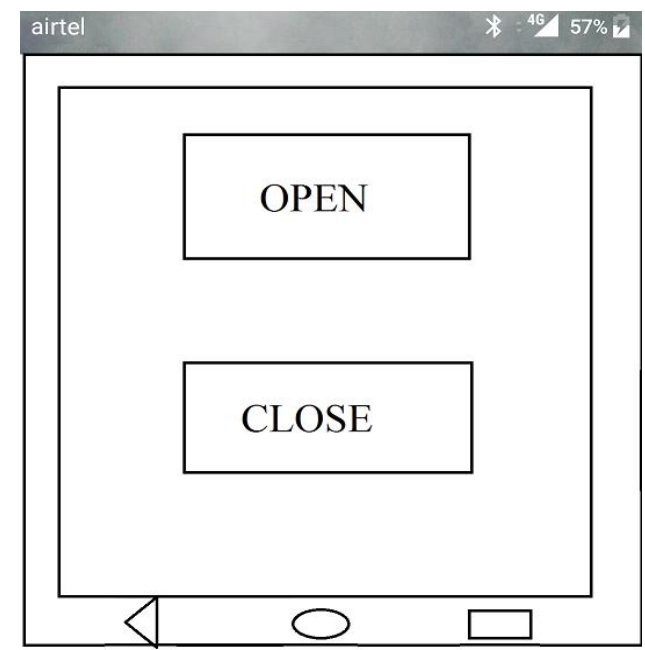

Figure 3c: Accessing door through Bluetooth

\section{B. GSM Module}

The process is initiated in the same application which is used for Bluetooth control. Select the SMS option in the android application which asks to enter a password pin for security. If the input security PIN is correct, the application takes the user to the messenger application. Here, the user can type either a "OPEN" or "CLOSE" text to perform the required operation and press the send button.

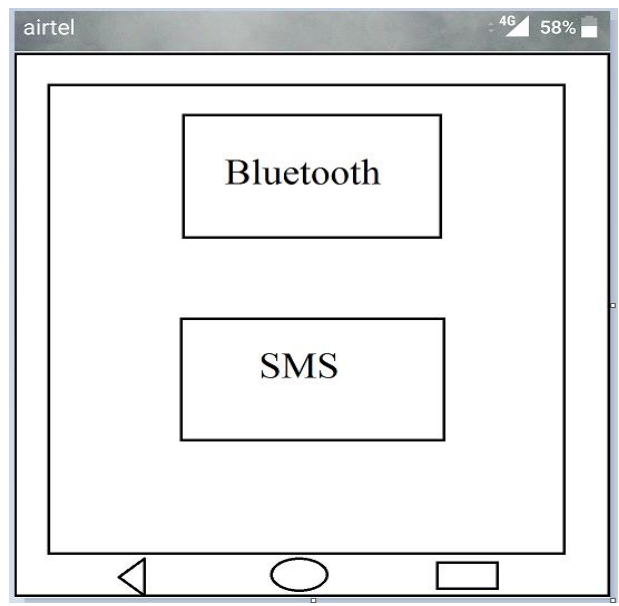

Figure 4a: First step in the application

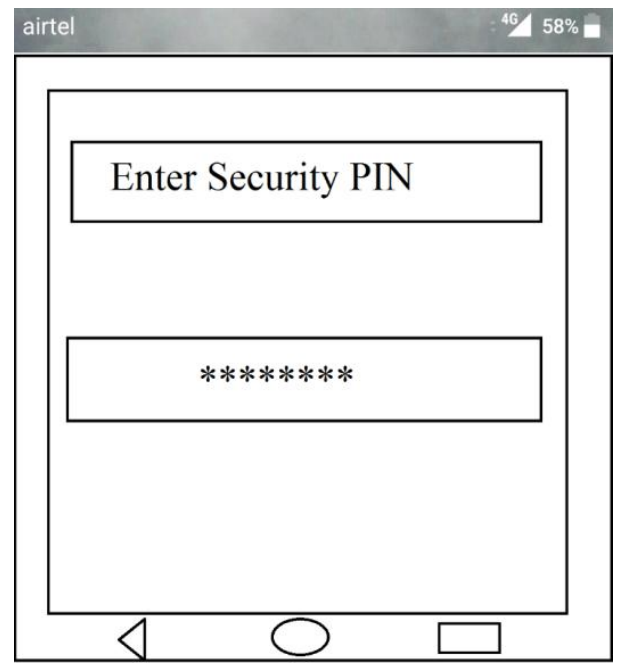

Figure 4b: Enter Security PIN to access lock 


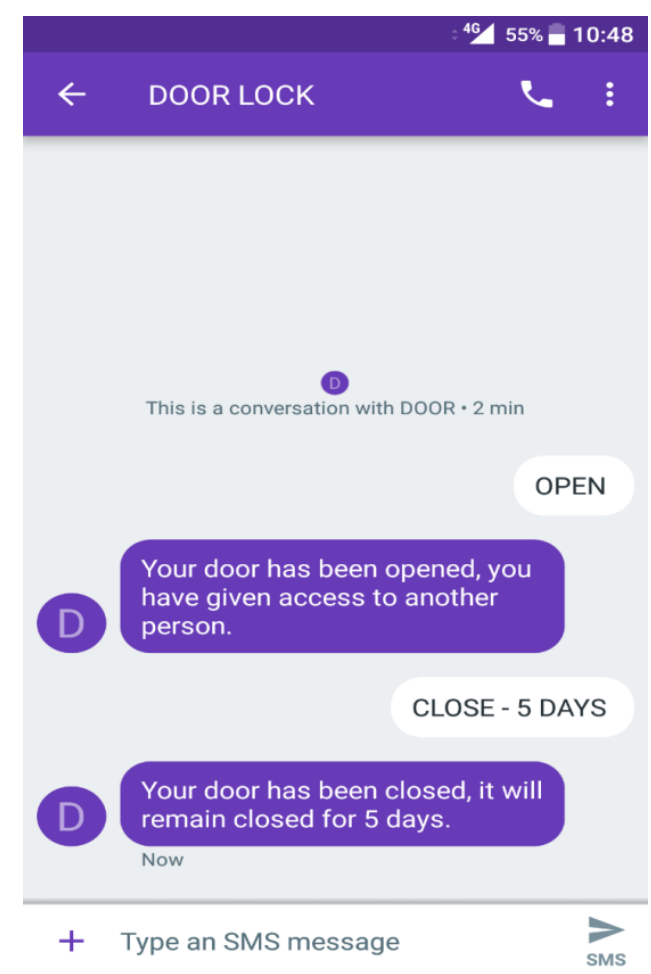

Figure 4c: Conversation with Door Lock

Here the application is designed in such a way, it has all the details of the GSM module embedded in the door lock system. The GSM module in the door lock receives the text message, decodes it and inputs the same into the microcontroller. The microcontroller actuates the servo motor based on the input given by the user. (This process is shown in figure $4 \mathrm{a}, 4 \mathrm{~b}$ and $4 \mathrm{c})$.

The introduction of GSM module can also be used in the case of a security breach. If a thief tries to access the door, a message can be sent to the owner's phone stating that the door was accessed by an unknown user. From seeing this message, further action can be taken by the user.

- $\quad$ Power supply to the Door lock module

The door lock system has an inbuilt back up battery along with normal power supply. In the case of failure of power supply, the battery will act as the main supply.

In case the battery of the phone dies, the door lock can easily be accessed by using the same Android Application from another borrowed phone as the password PIN in unique to the lock and not the mobile.

\section{III.CONCLUSION}

From this method, it can be clearly seen that along with security, convenience has also been given equal importance. The lock can be accessed from close as well as from long distances. This has also effectively reduced the number items carried by an individual in daily life. Wallets have already been incorporated into phones, now the keys can be implemented into it as well. The usability of this can be extended not only for house doors but also for security closets, bank lockers, car doors and bank vaults. This also aligns with the vision of a world inclined towards internet of things.

\section{REFERENCES}

[1] GSM/GPRS Module - Sparkfun https://www.sparkfun.com/ datasheets/Cellular\%20Modules/CEL-09533-User's\%20Ma...

[2] Serial port Bluetooth Module (Master/Slave): HC-05 - ITEAD Wiki-https://www.itead.cc/wiki/Serial_Port_Bluetooth_Module_ (Master/Slave) :_HC-05

[3] Journal of Material Science and Technology

[4] www.materialstoday.com/metal-finishing/features/profile-plametto-plating/

[5] J. Potts and S. Sukittanon, "Exploiting Bluetooth on Android Mobile Devices for Home Security Application," in Proceedings of IEEE SoutheastconOrlango, (2012), pp. 1-4

[6] Y. Park, P. Sthapit, and J. Pyun, "Smart Digital Door Lock for the Home Automation", in Proceedings of TENCON 2009, (2009), pp. 1-5.

[7] M. Roy, F. Hemmert, and R. Wettach, "Living Interfaces: The Intimate Door Lock," in Proceedings of the Third International Conference on Tangible and Embedded Interaction (TEI'09), (2009), pp. 45-46. 
[8] M. Khiyal, A. Khan and E. Shehzadi, "SMS Based Wireless Home Appliance Control System (HACS) for Automating Appliances and Security", Issues in Informing Science and Information Technology, vol. 6, (2009), pp. 887-894.

[9] U. Ogri, D. Okwong, and A. Etim, "Design and Construction of Door Locking Security System using GSMY", International Journal Of Engineering And Computer Science, vol. 2,no. 7, (2013), pp. 2235-2257.

[10]R. Satti, S. Ejaz, and M. Arshad, "A Smart Visitors' Notification System with Automatic Secure Door Lock using Mobile Communication Technology," International Journal of Computer and Communication System Engineering, vol. 2, (2015), pp. 39-44.

\section{Websites}

- www.iaarc.org

- www.instructables.com

- www.electronichub.org

- electricalengineeringschools.org

- $\quad$ www.jeeexplore.ieee.org

\section{BIOGRAPHIES}

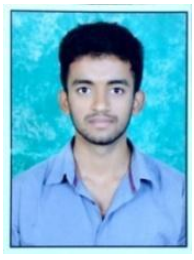

Mohan M who hails from Bangalore (Karnataka) is pursing B.E in Mechanical Engineering at RV College of Engineering, Bangalore. His area of interest are design and analysis of mechanical models and systems. Other interest includes aviation and aerospace.

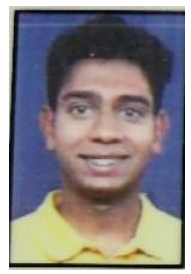

Vishal Kannan who hails from Bangalore (Karnataka) is pursing B.E in Mechanical Engineering at RV College of Engineering, Bangalore. His area of interest includes mechatronics, design, thermodynamics and physics. Other interests include finance, investment and emerging technologies. He was selected for and has successfully completed, a general management program for young leaders at Stanford University.

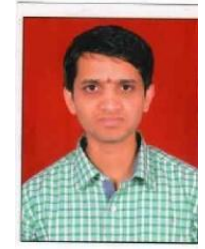

M Keshav who hails from Bangalore (Karnataka) B.E, M.Tech, works as an Assistant Professor in Mechanical Engineering at RV College of Engineering, Bangalore. His area of interest includes mechatronics, CNC programming, CAD CAM, energy management and industrial automation. He has 6 years of experience in teaching and 1 year in $R \& D$. 